\title{
A Novel Mutation Leading to Leptin Receptor Deficiency and Subsequent Childhood Morbid Obesity
}

\author{
Algariri Najla ${ }^{1}$, Alhabib Majed ${ }^{2, *}$, Alsaheel Abdulhameed ${ }^{3}$ \\ ${ }^{1}$ Pediatric endocrinology fellow, children's specialized hospital, King Fahad Medical City, Saudi Arabia. \\ ${ }^{2}$ Pediatric endocrinology consultant, Pediatric Endocrine Section, Royal Commission Hospital, Saudi Arabia. \\ ${ }^{3}$ Pediatric endocrinology consultant, children's specialized hospital, King Fahad Medical City, Saudi Arabia.
}

\begin{abstract}
Received: October 11, 2017; Accepted: October 31, 2017; Published: November 07, 2017
*Corresponding author: Dr. Alhabib Majed, Pediatric endocrinology consultant, Pediatric Endocrine Section, Royal Commission Hospital, Saudi Arabia.Email: drmajedus105@yahoo.com
\end{abstract}

\begin{abstract}
Leptin hormone is a product of the obese Leptin gene (Ob Lep Gene) is expressed primarily in Adipocytes . As fat increases in the fat cells this will lead to produce more leptin.

Leptin acts on leptin receptors, which are widely distributed to effect on energy homeostasis, neuroendocrine function and immune function. The leptin receptor is found in the surface of cells in many organs and tissues of the body including hypothalamus. The hypothalamus controls hunger and thirst as well as other functions such as body temperature, sleep, mood, fatigue and circadian rhythms. which makes leptin hormone is involved in the regulation of the body weight.

Both leptin deficiency and leptin receptor deficiency (leptin gene mutation) will cause morbid obesity.

In this report, we describe a 26-month-old boy with severe morbid obesity found to have a novel mutation in leptin gene causing congenital leptin receptor deficiency.
\end{abstract}

\section{Case Report}

A 26-month-old boy was referred to our pediatric endocrine clinic as a case of morbid obesity for further investigations and to rule out Cushing disease. He was born at term with a birth weight of $2 \mathrm{~kg}$ to a consanguineous parent. He started to gain weight with increased appetite at the age of 4 months. He was complaining of snoring and obstructive sleep apnea for the last 12 months. Clinically his weight was above 97th centile, and his height was at 25thcentile, his BMI 36 (6.3 SD above the mean), He had normal blood pressure and there was no acanthosis nigricans, striae and no organomegaly. Other systemic examinations were unremarkable and he had normal prepubertal male genitalia. His developmental assessment was appropriate to his age. He had no history of recurrent infections. No family history of severe obesity or similar illness.

Laboratory and radiological investigations revealed a:

TFT: TSH 1.1mIU/L (0.85-6.5), Free T4 12.9 pmol/L (12-22)

Renal profile: urea $2.6 \mathrm{moml} / \mathrm{L}(2.5-6.4)$, creatinine $24 \mu \mathrm{mol} / \mathrm{L}$ (20-49)
Lipid profile: cholesterol $3.32 \mathrm{mmol} / \mathrm{L}$ (3.63-5.15), HDL 0.72 $\mathrm{mmol} / \mathrm{L}$ (0.91-1.68),

LDL $1.99 \mathrm{mmol} / \mathrm{L}(0.00-3.4)$, triglyceride $1.88 \mathrm{mmol} / \mathrm{L}(0.00$ 1.70)

Bone profile: corrected serum calcium $2.44 \mathrm{mmol} / \mathrm{L}$ (2.24-2.74), Serum phosphate $1.76 \mathrm{mmol} / \mathrm{L}$ (0.87-1.45), Alkaline Phosphatase $272 \mathrm{U} / \mathrm{L}$

25 OH Vitamin D3:43.3nmol/L(50-250) ,PTH:3.9pmol/L (1.66.9)

ACTH: $1.9 \mathrm{pmol} / \mathrm{L}$ (1.6-13.9)

HbA1C 5.3\% (4.5-6.2\%), Random blood glucose $4.8 \mathrm{mmol} / \mathrm{l}$ (3.96.7)

Insulin 830.3 pmol/l (17.8-120), very high insulin level.

IGF1: 4.3nmol/L (6.6-39.4), IGFBP3: $2.4 \mathrm{mg} / \mathrm{L}$ (2.2-7.8)

FSH: 0.8 IU/L (1.5-12.4), LH: 0.1 IU/L (1.7-8.6)

Karyotype: $46 \mathrm{XY}$, normal male karyotype.

Low dose Dexamethasone suppression test: showed normal suppression of cortisol level.

FISH for Prader- Willi syndrome: was negative.

MC4R gene: was negative

Sleep study: showed obstructive sleep apnea and needed continuous positive airway pressure during sleeping.

Liver ultrasound: mild diffuse fatty liver changes.

Bone age: was consistent with his chronological age.

Hypothalamic and pituitary MRI: was normal.

Leptin level $31 \mathrm{ng} / \mathrm{mL}$, showed very high level in this age.

Leptin Gene result: A novel mutation of the leptin gene c. $1285+1 \mathrm{G}>\mathrm{A}$, 
Which leads to disruption of the canonical splice donor site of intron 10 , was identified.

\section{Discussion}

Obesity due to congenital leptin receptor deficiency is a form of monogenic obesity caused by a mutation in a single gene. The diagnosis of congenital leptin receptor deficiency can be easily overlooked. Morbid obesity starts in first few months of life and high leptin level can be a clue to the diagnosis which necessitates doing leptin gene.

Features of congenital leptin receptor deficiency are similar to leptin deficiency features which include: morbid obesity starts during early infancy associated with hyperphagia, hyperinsulinemia, high leptin level, may also have hypogonadotropic hypogonadism, altered immune function, reduced growth hormone secretion and hypothyroidism [1].

In humans, the ob (lep) gene is located on chromosome $7 q 32$ and consists of three exons and two introns that span 20 kilo bases $(\mathrm{kb})$ of DNA.

Novel mutations in the leptin receptor were identified before in two unrelated girls with obesity and increased bone mineral density [2].

Leptin receptor mutations are very rare and have been reported in 10 families. Two Egyptian cousins with leptin receptor mutations presented with severe early onset obesity, severe hyperphagia, hypogonadotropic hypogonadism and neuroendocrine/metabolic dysfunction [3].

Two novel homozygous Leptin receptor mutations were identified in two obese Pakistani kids, leptin levels were high in both probands, who were phenotypically indistinguishable from age-matched leptin-deficient subjects from the same population [4].
As we described in this report, a novel mutation in leptin gene c. $1285+1 \mathrm{~g}>\mathrm{a}$ was identified in a 26 -month-old boy with severe morbid obesity.

\section{Conclusions}

Consider congenital leptin receptor deficiency in a child with hyperphagia and severe morbid obesity starting in the first few months of life. Affected individuals have normal weight at birth but, they have rapid weight gain during infancy period due to continuous hunger and hyperphagia.

Subjects with leptin receptor deficiency may also have hypogonadotropic hypogonadism and some subjects may also have altered immune function, reduced growth hormone secretion and hypothyroidism.

Genetic counseling is very important step in the management of leptin receptor deficiency.

\section{References}

1. Dubern B, Clement K. Leptin and leptin receptor-related monogenic obesity. Biochimie. 2012;94(10):2111-2115. Doi: 10.1016/j. biochi.2012.05.010

2. Hannema SE, Wit JM, Houdijk ME, van Haeringen A, Bik EC, Verkerk AJ, et. al. Novel Leptin Receptor Mutations Identified in Two Girls with Severe Obesity Are Associated with Increased Bone Mineral Density. Horm Res Paediatr.2016;85(6):412-420. Doi: 10.1159/000444055

3. Mazen I, El-Gammal M, Abdel-Hamid M, Farooqi IS, Amr K. Homozygosity for a novel missense mutation in the leptin receptor gene (P316T) in two Egyptian cousins with severe early onset obesity.Mol Genet Metab. 2011;102(4):461-464. Doi: 10.1016/j. ymgme.2010.12.013

4. Saeed S, Bonnefond A, Manzoor J, Philippe J, Durand E, Arshad M, et. al. Novel LEPR mutations in obese Pakistani children identified by PCRbased enrichment and next generation sequencing. Obesity (Silver Spring). 2014 ;22(4):1112-1117. Doi: 10.1002/oby.20667 